\title{
Application Possibilities of Blockchain in Accounting
}

\author{
Péter Bálint Király*
}
* Dr. Péter Bálint Király, Internal PhD student of the Széchenyi István University in Győr, Faculty of Law, Department of Administrative and Financial Law. (e-mail: kiralypeterbalint@gmail.com)

\begin{abstract}
In recent decades technology has advanced rapidly, and inventions that have made our lives easier have emerged. Among the many life changing inventions, Blockchain facilitates our financial activities, for example banking, commerce and accounting, because it eliminates the need for a third party, thus saving us time and money. With its help, we can manage and record asset movements, contracts and their fulfilment, as well as other data by cryptographic methods. In the following article, firstly I will describe the concept and operation of Blockchain and the advantages of using it in the field of accounting. After that I will introduce the accounting principles, based on the Hungarian Accounting Act. Finally, I will address the legal questions raised by applying the accounting principles to Blockchain when they are used in the process of accounting.
\end{abstract}

Keywords: Blockchain; tax law; accounting

\section{Introduction}

In recent decades, technology has advanced rapidly, and inventions that have made our lives easier have emerged. In the following, I address the issue of Blockchain regulation, examining the legal challenges generated by technological innovation, including its impact on the current accounting regulation. Blockchain is already considered by many to be the most important invention of the $21^{\text {st }}$ century and is compared to the Internet in terms of importance. Blockchain is essentially a decentralised or distributed ledger that, due to cryptographic procedures, is capable of authenticating transactions, without the need for an intermediary. Blockchain allows us to trust third parties we do not know and therefore do not have enough information about them. In the past, in order for this trust to exist, we needed an intermediary trusted by both parties to ensure that the other was not deceived. For example, we needed financial institutions in order to prove that we have the amount of money or collateral needed for a particular transaction. Blockchain systems eliminate the need for a third party, thus saving us time and money, while allowing everyone to access and supervise transactions carried out through Blockchain. ${ }^{1}$

Blockchain allows transactions to be made anonymously. Applying it can bring many benefits in different areas of life. The purpose of its creation was to eliminate the failures of the traditional financial intermediary system, and to provide a faster, cheaper and more secure way of conducting financial transactions. With its help, we can manage and record asset movements, contracts and their fulfilment, as well as other data by cryptographic 
methods. In addition, it can ensure the transparency of transactions, verify the origin of goods, provide authorities with real-time, reliable and credible data, enable continuous collection of taxes immediately after a transaction without human intervention, etc. Its potential for use is endless and the recent emergence of Blockchain-based innovations has significantly accelerated, necessitating an examination of how Blockchain and other related technologies can be integrated into the current regulatory environment.

\section{The Operation of Blockchain}

In order to present the legal challenges, the concept and operation of Blockchain must first be described.

Blockchain is a distributed ledger or decentralised database that is publicly accessible and, through cryptographic procedures, authentically and unalterably captures recorded data (e.g. transactions) without any intermediary, in a merely peer-to-peer way. ${ }^{2}$

Blockchain is an implementation of Distributed Ledger Technologies (DLTs).

The Distributed Ledger Technology is a database based on a technology that enables the content to be simultaneously accessed, modified and authenticated by authorised personnel and, upon agreement, to be copied, shared and synchronised between participants, regardless of geographic boundaries. The essence of a centralised software system is that there is a central node (central computer) and all other nodes (computers) are connected to the central node, but these other nodes are not directly connected to each other. In contrast, in a distributed/decentralised system, like a blockchain, nodes (computers) are connected to each other without any central node among them. That is, the nodes communicate directly with each other, and not through a central node.

Blockchain is essentially a so-called peer-to-peer protocol, which means that it is a computer network whose users (or rather their computers functioning as nodes) communicate directly with one another without a central node (computer). P2P systems are distributed software systems that consist of nodes (computers) and thus make their computing resources (e.g. processing speed, storage, information distribution) directly accessible to others. When connected to a P2P network, users' computers become equal nodes in the system in terms of their roles and privileges. Although users are different in terms of available resources, all nodes in the system have the same functional capabilities and the same responsibility. As a result, all users' computers are both service providers and consumers. $^{3}$

The above properties mean that anyone can join Blockchain, and once connected, initiate transactions directly to each other, anonymously. Transactions are also authenticated by users through their computer capacity made available to Blockchain. During this process Blockchain wraps the information about the transactions in so-called blocks, and then these blocks are added to the Blockchain that serves as the ledger. An essential element of this process is the so-called consensus mechanism, which is needed to get computers to agree on Blockchain updates so that all computers will then have the same Blockchain data content. ${ }^{4}$ 
How does it work? I would like to illustrate the operation of Blockchain through the example of the Bitcoin-Blockchain Proof of Work consensus mechanism. The data about transactions are gathered into blocks every 10 minutes. Then the transactions included in the new block are authenticated by the nodes (e.g. they confirm that the buyer actually had the needed amount of cryptocurrency available for the transaction). 5 Thereafter, the transaction data set of the new block is supplemented by the so-called "header" of the previous block. This header actually works like a personal number. Each block has a unique header through which it can be identified. This means that each block refers to the preceding block and consequently the chain of transactions can be traced back to the original block containing its first transactions. Once the header of the previous block is added to the new block, the data contained therein begins to be encrypted by solving a cryptographic puzzle. ${ }^{6}$ (Cryptography was originally equivalent to encryption, but today it has become a stand-alone mathematical-informatics science, which is about protecting information by transforming and transmitting information, text and messages in a way that only those can understand, to whom the message was intended.) All the blockchain-running computers (the so-called miners) compete on which one can solve this cryptographic puzzle the fastest, because the first one to solve receives Bitcoin (or other cryptocurrency in case of other Blockchain systems) for their work. The new block is then added to the blockchain and shared on all computers in the system. ${ }^{7}$

When a sufficient amount of computer power is provided, Blockchain is able to record transactions reliably, as the entire Blockchain is constantly updated and shared among network members. That means that every single moment any participating computer can verify every transaction that has been recorded. ${ }^{8}$ Recorded transactions are virtually immutable once added to the Blockchain. This is because the complete Blockchain is present on all computers and each block refers to the preceding block. This means that if a hacker wants to change a transaction, they need to change not only the block that contains that transaction, but also the next one, and then the next one, and so on, since all blocks contain the header of the previous block. In addition, these changes would have to be made on more than half of the nodes of the Blockchain, since more than half of the computers are needed to reach consensus about transactions. ${ }^{9}$

\section{Advantages of the Blockchain Technology in Accounting}

The essence of accounting and auditing is to create mutual trust and to provide protection for investors. That is why the requirement of double-entry accounting has been introduced, which ensures the accuracy of the recorded data. As business companies grew and evolved, they increasingly needed external financial resources. However, investors only provided capital to a business company if they saw that their investment was paying off. The easiest way to check this was if the company in which they were investing disclosed information about their activities. Due to the information asymmetry between the company and the investor, the company can easily manipulate the data. This is why there is a need for external auditing of accounts, which can reduce information asymmetry and increase trust 
and thus the value of the company. Of course, conducting an external audit to detect accounting errors and fraud is also in the interest of the business, since the decision of potential investors is greatly influenced by whether they can rely on the information disclosed by the business. Because external auditing is done by people, it is not perfect either: it reduces the risk of errors and fraud, but it cannot detect all. ${ }^{10}$

The digitisation of accounting activities may provide a solution to this. However, this is made more difficult by the complex set of legal requirements which require, among other things, the authenticity of the recorded data. The purpose of the accounting rules is to prevent the possibility of forgery and the recording of false or misleading information. This is ensured by, among other things, various regular checks, extensive documentation of data, double-entry bookkeeping, etc., all of which are labour-intensive and costly activities and difficult to automate. At least that was the case until Blockchain appeared. ${ }^{11}$

As is clear from its concept, Blockchain is a technology that functions as a general ledger for transferring ownership and recording accurate financial information. The focus of the accounting profession's activities is to record, measure and communicate financial information, property rights and obligations, and to analyse that information. Based on this data, accounting professionals plan the best allocation of financial resources. For accountants, using Blockchain can greatly improve efficiency by reducing the cost of maintaining and reconciling ledgers, and reliably recording transaction chains and ownership of assets.

Applying Blockchain can help accountants' work by making the resources, rights and obligations of companies more transparent. In addition, it saves time for accountants, as transactions need not be recorded by accountants, as Blockchain will do it. ${ }^{12}$ Blockchain technology can also facilitate compliance with legal requirements, for example by assisting in double-entry bookkeeping, and the authenticity of recorded data no longer has to be verified by an external actor (auditor), as the Blockchain itself provides this. ${ }^{13}$ In addition, with the help of Blockchain, all of these activities are performed by the program itself without the need for an intermediary, in a transparent, secure, reliable and tamper-proof manner. ${ }^{14}$ The focus of the accountants' activities is thus expected to shift from data accounting to planning and the evaluation of Blockchain data. Blockchain is not able to answer all the questions that arise during the activities of a company. For example, you can credibly prove who owns an asset, but its value, condition, method of accounting, and placement in each category of financial statement still need to be determined by experts. ${ }^{15}$

\section{Accounting Principles}

Below I present the accounting principles required by Act C of 2000 on Accounting (hereinafter: Sztv.).

The basic principle of the Sztv. is the principle of going concern, which means that drawing up the financial report and the accounting records shall be based on the assumption of the economic entity's capacity to sustain operations in the foreseeable future and on its ability to continue its activity, and the termination of or a considerable reduction, for any reason, in the operation is not expected. ${ }^{16}$ It assumes that the business is created to operate profitably in the long run. The other principles must also be interpreted in this light. 
According to the true and fair view principle, assets shown in the books and contained in the financial report shall be such that they can be found and verified as in fact being in existence, tenable and verifiable. The measurement of such assets shall be carried out in accordance with the valuation principles prescribed in the Sztv., as well as with the relevant valuation procedures. ${ }^{17}$

Based on the principle of completeness, economic entities shall keep accounts of all economic events, the effect of which on the assets and liabilities, as well as on profits, are to be shown in the financial report, including the economic events which pertain to the financial year in question that became known after the balance sheet date but before the date of closing, as well as the ones generated by the economic events of the financial year ending on the balance sheet date, that had not yet taken place prior to the balance sheet date but became known prior to the closing date of the balance sheet. ${ }^{18}$

According to the principle of prudence, no profit shall be recognised where the financial realisation of the revenues and certain items of income are uncertain. When determining the profit or loss for the year, foreseeable liabilities and potential losses shall be taken into account and shall be covered by provisions, even if such liabilities or losses become apparent only between the date of the balance sheet and the date on which it is drawn up. Depreciation impairment losses shall be accounted for, regardless of whether the income statement for the year shows a profit or a loss. ${ }^{19}$

The principle of matching means that when determining the profit or loss for a certain period of time, the revenues recognised for a given period of activities and the costs (expenditures) directly associated to such revenues shall be taken into account, regardless of the financial settlement. The revenues and costs shall relate to the period in which they were incurred for economic purposes. ${ }^{20}$

Based on the principle of accruals, the consequences of economic events concerning two or more financial years shall be recognised under the revenues and costs of the period in question in the proportion in which they are incurred between the underlying period and the accounting period. ${ }^{21}$ For example, if a business leases an office for 3 years and receives a 3-year lease in advance, it may not account for the full 3-year rent for the year it was issued, but only show $1 / 3$ of that year.

According to the principle of grossing up with the exceptions laid down in the Sztv., revenues and costs (expenditures), and receivables and liabilities may not be set off against one another. ${ }^{22}$ This means that liabilities, receivables and revenues should be recorded separately, because if these could be offset, the data would no longer give a credible picture of the company.

The principle of substance over form means that in the financial report and in the relevant accounting records, economic events and transactions shall be shown and accounted reflecting their economic substance and in accordance with the basic principles and relevant provisions of the Sztv. ${ }^{23}$ This means that in accounting, not the legal content is primary, but the economic. However, when recording economic events and transactions, the principles of the Sztv. and the relevant regulations must be followed. (For example, in the case of a finance lease, the leased asset must be shown to the lessee, even though the legal ownership of the asset is with the lessor. Because the lessee possesses the asset in the economic sense of the asset as if it were the owner, it will order the lessee to account for it.) 
According to the principle of valuation on an item by item basis, assets and liabilities shall be entered and evaluated item by item in the course of bookkeeping and preparing the report. That is, each item must be separately identified and recorded as specified in the accounting policy of the company. ${ }^{24}$

The principle of materiality means that for the purposes of the financial report, information is material if its omission or misstatement could influence - within reason - the economic decisions of users taken on the basis of the financial report. The materiality of individual items shall be assessed in the context of other similar items. It is the entity's responsibility to determine in its accounting policies exactly which information is material to that particular entity. ${ }^{25}$

Based on the principle of cost-benefit, the usefulness (utility) of any information published in the financial report (balance sheet, profit and loss account, notes on the accounts) shall be commensurate with the costs of producing that information. ${ }^{26}$

According to the principle of consistency, in respect of content and formal requirements, and of the financial report and the underlying accounting records, constancy and comparability shall be provided for. ${ }^{27}$ Compliance with this requirement is facilitated by the models annexed to the Sztv. and the EU Directives.

The principle of clarity means that the accounting records and the financial report shall be prepared in a concise, comprehensible form in accordance with the Sztv. ${ }^{28}$

Based on the principle of continuity, the opening data of a financial year shall be identical to the corresponding closing data of the previous financial year. In consecutive years the valuation of assets and liabilities, and the assessment of profit of loss may be altered only in accordance with the relevant provisions of the Sztv. ${ }^{29}$ If the valuation principles applied in the process of drawing up the balance sheet for the previous year have been changed, the factors causing the change, and the quantified effect thereof shall be detailed in the notes on the accounts. ${ }^{30}$

\section{The Application of the Accounting Principles on Blockchain}

In the previous chapters, the operation of the Blockchain technology, its conceptual basis, the advantages of its application in the field of accounting, and the accounting principles have been described. Blockchain, while it automates bookkeeping, creates the necessary trust between the parties without resorting to intermediaries and saves us time and money, but does not solve all the problems. Indeed, from a legal point of view, many issues need to be addressed. In the following, I will address the application challenges of Accounting Principles on Blockchain.

In my opinion, among the accounting principles described above, there are those that are not influenced by whether a particular company uses Blockchain or traditional tools for accounting.

The principle of going concern is also relevant in case of Blockchain, since accounting must continue to be based on the fact that the enterprise is engaged in business indefinitely and thus can continue to operate in the foreseeable future. 
The principle of substance over form is also an inescapable principle. It requires that in the financial report and in the relevant accounting records, economic events and transactions shall be shown and accounted reflecting their economic substance and that the principles and relevant requirements of the Sztv. should be followed. In my view, adhering to this principle is only a matter of programming.

The same is true of the principle of completeness, since the accounting technology does not change the fact that an enterprise is required to account for all economic events that have an impact on its assets and liabilities and on the profit or loss for the current year. Because economic events are recorded in real time, the economic events which pertain to the financial year in question that became known after the balance sheet date but before the date of closing are definitely recorded. However, it should be noted that, with proper programming, the technology can be used not only to look at periodic balance sheets and profit and loss statements, but also to take a look at the current financial position of the enterprise at any time.

However, there are also some principles that are easier to comply with by the use of Blockchain.

The principle of clarity requires that the accounting records and the financial report be clear and understandable. Blockchain makes it easier to produce various statements and statistics that help you understand the financial position and activity of a particular enterprise.

According to the principle of prudence, it is forbidden to recognise a profit if the revenue, the financial realisation of the income is uncertain. The essence of Blockchain is to verify that a financial transaction has actually taken place, so applying it excludes the recognition of a profit for which the financial realisation of revenue is uncertain.

The obligations set out in the principles of matching and continuity - that last year's closing data should be consistent with next year's opening data, and that revenues and expenses should relate to the period in which they are economically incurred - can also be easily met, as Blockchain records the chain of economic events that have already taken place. It must be noted that, if the Blockchain data capture methods change as a result of changes in the legal environment or accounting policies, then, in accordance with the principle of continuity, its quantified effects must be disclosed separately.

Compliance with the principle of grossing up is not a problem either, as the individual transactions in the Blockchain are recorded separately. In this respect, states must ensure that the participants in the transactions do not make an agreement outside the Blockchain, and not just transfer the amount determined as a result of the set-off. The same applies to the principle of valuation on an item by item basis, as Blockchain is able to record individual items separately in a way specified in the accounting policy.

In accordance with the principle of materiality, only material financial events need to be recorded in the financial reports. With the help of Blockchain, not only the material but all economic events can be recorded. However, it is debatable whether we really want all the data to be included in the report, as it is important to maintain transparency. Nonetheless, the technology allows us to authentically record and store a large amount of data and to produce reports and statistics on different subjects that meet the needs of the user. 
According to the principle of cost-benefit, the usefulness of the information disclosed should be proportionate to the cost of producing the information. In my view, Blockchain can widen the scope of information to be provided, as it can produce more information at a lower cost about companies. All of this can be beneficial to investors, as companies become more transparent.

However, compliance with the principle of accruals may be problematic because transaction data are immediately recorded in the Blockchain and there is no possibility to recognise economic events concerning two or more financial years under the revenues and costs of the period in question in the proportion in which they are incurred between the underlying period and the accounting period. Of course, this is really only a matter of programming, but it should be reconsidered whether this principle should be applied to companies using Blockchain. Similarly, consideration should be given to whether the principles associated with a specific time period are relevant to a system that provides data at any time, for any time period, and whether changes in the financial state of the company in question can be tracked in real time.

Based on the principle of consistency, enterprises shall provide the consistency and comparability of their accounting records and financial reports. In connection to this, the issue of interoperability arises. Currently, individual states have begun to develop their Blockchain on their own, which are governed by their own laws. This can cause problems for companies involved in international trade or with subsidiaries. These must apply the Blockchain of each state in which they operate in order to comply with the regulations of each state. It would therefore be advisable to set up an international Blockchain that complies with international accounting standards. This, of course, first and foremost requires the creation of a fully unified international system of requirements. Alternatively, we may create a method that can easily convert data from one national Blockchain to another.

The biggest challenge, in my opinion, is to comply with the true and fair view principle. It can be problematic that the integrity of the recorded data can be assured only if more than half of the computer capacity connected to the system is owned by the state (or at least by a person or body whose good faith is beyond doubt). Blockchain, as explained above, is a distributed ledger that we can trust because all the computers in the network have the registered data, and it is theoretically impossible to change the data set because in order to do so one needs to hack all computers (or at least more than half them). In case of Blockchain, we do not have to rely on a specific person or institution (as it is not a specific person or institution doing the registration tasks), but on the system itself, on the code of the program. Blockchain is thus potentially suitable for replacing intermediaries in different fields.

The disadvantage of Blockchain systems is that Blockchain can only guarantee the integrity of the input data, but not the authenticity of the input data. So, even if we can make sure that no one has tampered with the input, we still cannot use Blockchain to ensure that the input is accurate. ${ }^{31}$ The Blockchain network authenticates the different facts and data with the agreement of the individual nodes, but it can just as easily happen that there is an agreement between the members of the network regarding a fact or data that is not true. From this point of view, Blockchain can also be "hacked" not in the traditional 
sense, not by altering the data stored in the Blockchain, but by including false information in the block. ${ }^{32}$

It should also be noted, however, that this problem also arises with the accounting methods currently used, since accountants may enter incorrect or even false data in the ledger. As explained above, that is the reason why the institution of audit was introduced. At this point, the problem arises that, if the data recorded on the Blockchain is also audited by an outsider institute (i.e. auditor), then we have essentially brought back a centralised element into the Blockchain system, which is otherwise based on the principle of decentralisation. Although legally it is completely acceptable, because it is one of the most important goals of accounting principles to ensure the accuracy of the data. However, Blockchain is created precisely for the purpose of directly capturing the necessary data in a system without the involvement of an intermediary (in this case, an auditor, and, moreover, the state), whereby the program itself creates trust between the parties. Subsequent state control over the data registered thus goes against the very essence of Blockchain, the introduction of which would certainly face considerable opposition amongst the Blockchain enthusiasts. ${ }^{33}$

\section{Further Challenges: Immutability of the Recorded Data}

The essence of the right to forget is that everyone should have the right to request the deletion of their data if its use does not comply with data protection rules. ${ }^{34}$ Furthermore, there may be cases where the law states that after a certain period of time stored data must be deleted from the register. In addition, data is uploaded to the system by people and people make mistakes, so we cannot rule out incorrect data entry, which may also need correction. What happens if I enter data incorrectly? How can the data be erased or corrected in a system that relies on the fact that the input data cannot be deleted or modified later? The data once added to the Blockchain cannot be changed or deleted, or at least a so-called hard fork is required to do so. ${ }^{35}$ Hard fork is used when the Blockchain protocol is modified in such a way, that a previously created block becomes invalid. This can virtually delete previously recorded data in the event of an error. Of course, this also requires the consent of the majority of the nodes. ${ }^{36}$

This raises another problem: what happens when, despite a legal provision or a judicial or regulatory decision, developers cannot delete data stored in the Blockchain due to a lack of consensus? What happens, for example, if a central bank's decision in the interest of inflation cannot be enforced on the Blockchain because users are voting against it? And what happens if users will not collect the tax that the state intends to collect on the Blockchain? In this case, the members are risking of acting illegally. The consequences of invalidity and nullity could be applied as civil law consequences. That is, they create a chain of virtually void contracts on the Blockchain by not modifying the Blockchain protocol in line with changes in legislation. In practice, this will motivate the community to vote in favour of the amendment, as a chain reaction would also jeopardise the validity of their contract. But who can say that a transaction or Blockchain as a whole is illegal? In case of a DAO, it is practically the community, not a court of justice. (The development of smart 
contracts itself has the effect that instead of the court, the program itself says that a party has behaved in an unlawful manner.) But what happens when users abuse their power to vote for a hard fork, though no illegal activity occurred, but they do have an interest in overwriting previous transactions?

A related problem is whether the Blockchain and the code as the law principle are almighty. In principle, all contracts can be rewritten into smart contracts that are selfexecuting, meaning you do not have to go to court in case of a legal debate. In case of an interest on late payments, this works easily: if the buyer does not pay until the $31^{\text {st }}$ of July, the purchase price paid by the buyer will be automatically increased by the amount of the interest on late payments. But what happens, for example, in case of an accident? A smart contract cannot tell who is responsible for the damage. That is, if, for example, we turn an insurance contract into a smart contract, then who tells the smart contract that the insured person actually caused the damage, and so the insurance amount is due. How can a cooperation obligation be coded? It cannot be written in bits because certain legal concepts are so complex that they cannot be simplified into logical (yes or no; if... then... because if not...) relationships. How could a code be a law if the legislators themselves or the lawyers drafting the contract are not able to incorporate all life situations and their legal solution into law or contracts? Why do we think programmers can do this? (Of course, this is only true as long as we do not have artificial intelligence capable of analogy and thus able to interpret complex concepts from the previous case law, such as equity.) $)^{37}$

This leads us to the conclusion that there is still a need for an external body (courts or authorities) with appropriate authority, control, oversight and rights to decide that a transaction, a combination of transactions and the operation of the Blockchain itself is unlawful or not. This decision must also be enforceable in such a way that the unlawful act cannot be lawfully continued, that is, it cannot legitimise the block that needs to be modified in the system (e.g. by continuing the Blockchain based on an illegal transaction, like in the case of Ethereum). From this point of view, it would be advisable for both courts and authorities to operate in a Blockchain, and when a decision is made, it would be included in the system.

So, in the end, we reintroduced the state as the third party. Of course, the problem here (which is not primarily legal, but more technological in nature) is how the state, a centralised power, can enter into a decentralised system in which the basic principle is the lack of intermediary institutions and independence from any central power? How can the benefits of a decentralised organisation be secured in a way that, if necessary, the state intervenes in the Blockchain? After all, allowing the state at any time to interfere with the operating principles of the Blockchain or the data recorded therein immediately raises the risk of abuse and corruption.

\section{Conclusion}

Blockchain can bring about changes that make life much easier for us. For this reason, we can safely consider it the most important invention since the advent of the Internet. In my paper I introduced the operation and conceptual foundations of Blockchain. I thought it 
necessary to explain it because, in my opinion, only by understanding its operating mechanism can we identify the points of legal concern and ask the relevant questions. As stated above, Blockchain is essentially a decentralised or shared ledger that, due to cryptographic procedures, is capable of authenticating transactions, without the need for an intermediary or body.

All in all, Blockchain allows us to rely on third parties that we do not know and about whom we do not have information affecting our risk-taking, even without recourse to intermediaries. Due to all these features, Blockchain can fundamentally change the field of accounting as they save businesses time and money while providing the state and investors with reliable data about businesses and their operations, all this in real time. As explained above, Blockchain is fundamentally consistent with accounting principles, but we must also see that it does not solve all the problems and, in fact, raises a number of issues from a legal point of view. Among these are the challenges related to the authenticity and immutability of the recorded data, interoperability, business secrets and jurisdiction.

The issues raised cannot be left unanswered, and their solution is even more needed, as the technologies described above are used more and more widely. Just think about the fact that even the largest audit firms have already begun to develop their own Blockchain because they do not want to lag behind in innovation competition. ${ }^{38}$ The process initiated by Blockchain is irreversible. The question therefore is, first and foremost, how lawmakers respond to the phenomenon. In this respect, I believe that the most important thing is to find an internationally coherent solution, since Blockchain is a cross-border innovation providing a service across the world via the Internet. Uniform regulation could ensure that the economic potential of Blockchain can be exploited more smoothly. However, legislators should also make sure that the regulations they introduce do not hinder innovation, but support, where possible, the development of Blockchain and related technologies. 


\section{References}

1 Joseph J. Bambara, Paul R. Allen, Blockchain: A Practical Guide to Developing Business, Law, and Technology Solutions, 15 (New York, McGraw-Hill Education, 2018).

2 Primavera De Filippi, Aaron Wright, Blockchain and the Law: The Rule of Code, 13-14 (London, Harvard University Press, 2018). DOI: https://doi.org/10.2307/j.ctv2867sp

3 Daniel Drescher, Blockchain Basics - A Non-technical Introduction in 25 Steps, 23 (New York, Apress, 2017). DOI: https://doi.org/10.1007/978-1-4842-2604-9

4 David Schwartz, Noah Youngs, Arthur Britto, The Ripple Protocol Consensus Algorithm (2014).

5 Mayukh Mukhopadhyay, Ethereum Smart Contract Development-Build Blockchain-based Decentralized Applications Using Solidity, 15-18 (Birmingham, Packt Publishing, 2018).

6 Drescher, supra n. 3, at 23. https://doi.org/10.1007/978-1-4842-2604-9

7 Don Tapscott, Alex Tapscott, Blockchain Revolution: How the Technology Behind Bitcoin Is Changing Money, Business and the World, 28-32 (London, Portfolio Penguin, 2016).

8 Hossein Kakavand, Nicolette Kost De Sevres, Bart Chilton, The Blockchain Revolution: An Analysis of Regulation and Technology Related to Distributed Ledger Technologies, 4-5 (2016). https://doi.org/10.2139/ssrn.2849251

9 Sarah Wurfel, Blockchain is unhackable but these are 5 possible vulnerabilities of "the new Internet", in Blockchain Crypto Journal, December 1 (2018).

10 Ting Yu, Stanley Lin, Qingliang Tang, Blockchain: The Introduction and Its Application in Financial Accounting, in The Journal of Corporate Accounting \& Finance, vol. 29, no. 4 (2018). DOI: https://doi. org/10.1002/jcaf.22365

11 Deloitte, Blockchain Technology. A game-changer in accounting? www2.deloitte.com/content/dam/Deloitte/ de/Documents/Innovation/Blockchain_A\%20game-changer\%20in\%20accounting.pdf (accessed 18 August 2019).

12 ICAEW, Blockchain and the future of accountancy, www.icaew.com/technical/technology/blockchain/ blockchain-articles/blockchain-and-the-accounting-perspective (accessed 18 August 2019).

13 Deloitte, supra n. 11.

14 Yu, Lin, Tang, supra n. 10. https://doi.org/10.1002/jcaf.22365

15 ICAEW, supra $n .12$.

16 Sztv. $15 \$(1)$.

17 Sztv. $15 \$(3)$.

18 Sztv. $15 \S(2)$.

19 Sztv. $15 \$(8)$.

20 Sztv. $15 \$(7)$.

21 Sztv. $16 \$(2)$.

22 Sztv. $15 \$(9)$.

23 Sztv. $16 \$(3)$.

24 Sztv. $16 \$(1)$.

25 Sztv. $16 \$(4)$.

26 Sztv. $16 \$(5)$.

27 Sztv. $15 \$(5)$.

28 Sztv. $15 \$(4)$.

29 Sztv. $15 \S(6)$.

30 Sztv. $46 \S(2)$.

31 Péter Bálint Király, A blokklánc-technológia nemzetközi kereskedelmi jogi összefüggései, 27, in Külgazdaság, vol. 63, no. 3-4 (2019).

32 Mike Bullock, Blockchain in Plain English (2017).

33 Király, supra n. 31, at 27.

34 Robert Kirk Walker, The Right to be Forgotten, 272, in Hastings Law Journal, vol. 64, no. 1 (2012). http://

35 Bambara, Allen, supra n. 1, at 79-80. 
36 Philipp Hacker, Corporate Governance for Complex Cryptocurrencies? A Framework for Stability and Decision Making in Blockchain-Based Organizations (November 22, 2017), 140-166, in Philipp Hacker, Ioannis Lianos, Georgios Dimitropoulos, Stefan Eich (eds.), Regulating Blockchain. Techno-Social and Legal Challenges (Oxford, Oxford University Press, 2019). DOI: https://doi.org/10.2139/ssrn.2998830

37 Josias N. Dewey, Shawn S. Amuial, Jeffrey R. Seul, The Blockchain: A Guide for Legal and Business Professionals, 49-50 (Danvers, MA., Thomson Reuters, 2016).

38 Stephen O'Neal, Big Four and Blockchain: Are Auditing Giants Adopting Yet? (2019). 